\title{
Crueira: resíduo agroindustrial sólido rico em amido
}

Crueira: agro-industrial solid waste rich in starch.

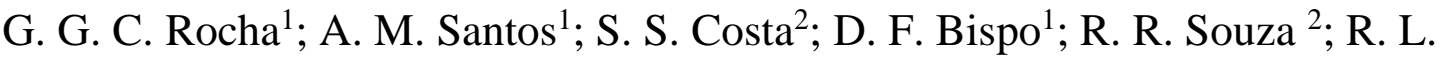 \\ Pagano $^{2} ;$ C. F. Silva ${ }^{2 *}$ \\ ${ }^{1}$ Departamento de Engenharia Química/ Laboratório de Bioquímica Industrial/ Universidade Federal de Sergipe, \\ 49100-000, São Cristóvão-Sergipe, Brasil. Tel. +55 (79) 2105-6677.
}

${ }^{2}$ Programa de Pós-Graduação em Engenharia Química/ Universidade Federal de Sergipe, 49100-000, São Cristóvão-Sergipe, Brasil. Tel. +55 (79) 2105-6677.

*ferrazcristina@ufs.br

(Recebido em 15 de março de 2016; aceito em 22 de abril de 2016)

A mandioca é um dos principais alimentos cultivados nos países subdesenvolvidos, possuindo destaque em diversos setores da sociedade. A mandioca é essencial para a base da alimentação de famílias e animais, além de gerar renda e empregos com importante participação socioeconômica e industrial. O Brasil representa um dos maiores produtores dessa tuberosa e seu processamento é comumente utilizado para a fabricação de fécula e farinha. No entanto, durante a produção da farinha são gerados vários resíduos, dentre deles a crueira. O objetivo do presente estudo foi caracterizar o resíduo sólido, crueira, gerado no processo de obtenção da farinha de mandioca que é descartado sem qualquer tratamento prévio. Foram caracterizados sete parâmetros físico-químicos do resíduo, compreendendo umidade, $\mathrm{pH}$, teor de cinzas, teor de amido, teor de lipídeos, fibra bruta e proteínas. Os resultados das análises físico-químicas demonstraram que o resíduo sólido estudado possui alto teor de amido $(82,00 \pm 0,58)$ e baixo teor de cinzas $(1,52 \pm 0,03)$. Portanto, a crueira representa um resíduo potencial que pode ser usado como fonte de amido em processos biotecnológicos de bioconversão.

Palavras-chave: crueira, caracterização, resíduo

The cassava is one of the main food grown in the developing countries, it has an important role in various sectors of society. It is essential as food base to many family and animals furthermore generates income and jobs and has an important role in the industry. The Brazil presents itself as a major producer of this tuberose and its processing is used for the manufacture of starch and flour. However, during the production of flour, are generated various by-products, one of them is crueira. The aim of this study was to characterize the solid residue, crueira, generated in the process of obtaining cassava flour, which is disposed without any previous treatment. Seven physical-chemical parameters of the residue were characterized, comprising moisture, $\mathrm{pH}$, ash content, starch content, lipid content, crude fiber and protein. The results of physicochemical analysis showed that the solid residue studied has a high starch content $(82.00 \pm 0.58)$ and low ash content $(1.52 \pm 0.03)$. Therefore, the potential crueira represents a residue that can be used as a source of starch in biotechnological processes bioconversion.

Keywords: crueira, characterization, residue

\section{INTRODUÇÃO}

Há cerca de nove mil anos a mandioca, que é uma planta perene, foi domesticada por populações na região de transição entre a Floresta Amazônica e o Cerrado onde, atualmente, estão localizados os estados de Rondônia, Mato Grosso e Amazonas. Ao chegarem ao Brasil, no início do século XVI, a mandioca era um dos alimentos básicos das populações indígenas [1]. Ao longo da história, a mandioca foi disseminada por todo o mundo pelos colonizadores produzindo um grande número de variedades com adaptação a diversos ecossistemas. A planta é cultivada em solos tropicais com reduzida disponibilidade de nutrientes, tolera desde altas precipitações, como as condições climáticas da Região Amazônica, até as deficiências hídricas 
do Semiárido. A espécie de mandioca mais utilizada no Brasil é a Manihot esculenta que tem capacidade de armazenar quantidade significativa de amido nas raízes [2].

Atualmente, a mandioca é um dos principais alimentos cultivados nos países subdesenvolvidos, é essencial para a base alimentar de mais de 800 milhões de pessoas, está entre as dez culturas em maior volume de produção no mundo e tem o Brasil como quarto maior produtor global [3]. É cultivada em todas as regiões do país por pequenos agricultores para o consumo familiar ou para abastecer pequenos negócios locais. Além de ser uma importante base de alimentação humana e animal, é também uma fonte de amido atraente para as indústrias, tornando-se importante na geração de emprego e renda [1].

A mandioca, que é essencial para a agricultura brasileira e apresenta importante papel socioeconômico em vários países tropicais, é utilizada principalmente na produção de fécula e farinha [4]. No entanto, durante o seu processamento vários resíduos são gerados. Dentre os resíduos gerados está a crueira, a qual corresponde ao resíduo sólido proveniente do processamento da raiz de mandioca para a produção da farinha. Esse resíduo possui estrutura fibrosa constituída das raízes e entrecascas [5].

De acordo com IBGE [6], o Brasil deverá colher uma safra de 24 milhões de toneladas de mandioca, com um acréscimo de 3,9\% em relação a 2014. Araújo et al [7] demonstram que uma tonelada de mandioca gera $15,4 \mathrm{~kg}$ de crueira, sendo que essa quantidade pode variar com o tempo de coleta, tipo de cultivo e ajustes do processo. A reutilização desse resíduo é, portanto, essencial, pois contribui para a redução do acúmulo de lixo orgânico, minimizando seu impacto ambiental.

Diante a crescente necessidade de buscar maior utilização para os resíduos agroindustriais e desenvolver processos que representem uma alternativa para a transformação desses materiais em produtos de maior valor agregado, o objetivo do presente estudo é realizar a caracterização físico-química da crueira e avaliar o seu potencial biotecnológico. Pois, determinar a composição físico-química se traduz não só nos fatores de impacto ambiental provocado pelo simples descarte do resíduo, mas também na busca por um valor econômico para o mesmo, possibilitando a geração de renda para os pequenos produtores de mandioca.

\section{MATERIAIS E MÉTODOS}

A crueira foi disponibilizada por casas de farinhas pertencentes ao sistema de agricultura familiar do município de São Cristóvão, Sergipe. Inicialmente a crueira foi seca em estufa a 60 ${ }^{\circ} \mathrm{C}$ por $18 \mathrm{~h}$ e em seguida resfriada em dessecador até temperatura ambiente. Após esse tempo, o resíduo foi homogeneizado até atingir o aspecto de farinha e dessa forma foi possível realizar os procedimentos de caracterização. Todos os ensaios foram realizados em triplicata e para a obtenção dos resultados foram realizadas as médias e desvios padrão para cada parâmetro analisado.

\subsection{Determinação do teor de umidade}

O teor de umidade da crueira foi determinado pelo sistema de secagem direta em estufa a $105^{\circ} \mathrm{C}$ até peso constante, segundo a metodologia descrita por Pregnolatto e Pascuet [8].

$$
\frac{100 m}{P}=\% \text { umidade }
$$

Sendo:

$m=$ peso em gramas de água evaporada após secagem;

$\mathrm{P}=$ peso em gramas da amostra.

\subsection{Determinação do $\mathbf{p H}$}

Para a determinação do $\mathrm{pH}$, uma solução homogênea com a crueira foi previamente preparada, seguindo a metodologia descrita por Pregnolatto e Pascuet [8]. O pH dessa solução foi determinado através de um medidor de $\mathrm{pH}$ devidamente calibrado. 


\subsection{Determinação do teor de cinzas}

O teor de cinzas na crueira foi determinado utilizando a metodologia de incineração em mufla a $550^{\circ} \mathrm{C}$ até peso constante [9].

$$
\frac{100 \mathrm{~N}}{\mathrm{P}}=\% \text { de cinzas }
$$

Sendo:

$\mathrm{N}=$ peso em gramas de cinzas;

$\mathrm{P}=$ peso em gramas da amostra.

\subsection{Determinação do teor de lipídeos}

Para a determinação de teor de lipídeo na crueira foi utilizado o método de extração direta em Soxhlet. A amostra de crueira foi transferida para o aparelho extrator e adicionado éter referente a 1 e $1 / 2$ Soxhlet sobre o papel contendo a amostra no extrator. Um condensador de bolas foi adaptado ao extrator. O processo foi mantido sob aquecimento e em refluxo contínuo por 8 horas, correspondendo a cinco gotas por segundo. O resíduo extraído foi transferido para estufa a $105^{\circ} \mathrm{C}$ por um período de uma hora. O procedimento de remoção do solvente e pesagem da amostra foi repetido até peso constante [9].

$$
\frac{100 \mathrm{~N}}{\mathrm{P}}=\% \text { de lipídeos }
$$

Sendo:

$\mathrm{N}=$ peso em gramas de lipídeos;

$\mathrm{P}=$ peso em gramas da amostra.

\subsection{Determinação do teor de amido}

Para a determinação do teor de amido foi inicialmente realizada uma hidrólise ácida para obtenção da glicose, seguindo a metodologia descrita por Carvalho et al [10]. Através da titulação com uma solução de Fehling foi possível quantificar a quantidade de glicose produzida e posteriormente realizar a conversão da glicose em amido.

$$
\frac{\mathrm{FC} \times 500 \times 100 \times 0,9}{\mathrm{~V} \times \mathrm{P}}=\operatorname{Amido}(\%)
$$

Sendo:

$F C=\frac{V_{\text {glicose }} 0,5}{100}$

$\mathrm{V}=$ volume em $\mathrm{mL}$ da solução da amostra gasto na titulação;

$\mathrm{P}=$ peso da amostra.

\subsection{Determinação dos teores de fibra bruta e proteínas}

A determinação dos teores de fira bruta e proteínas foram analisadas no Instituto Tecnológico e de Pesquisas do Estado de Sergipe (ITPS) em Aracaju SE.

\section{RESULTADOS E DISCUSSÃO}

O processo de secagem e homogeneização do resíduo permitiu um aspecto mais uniforme semelhante a uma farinha de cor branca com um perfil de partículas finas. Esse processo de homogeneização permite o aumento da superfície de contato facilitando a penetração do calor e 
o ataque de ácidos durante a sacarificação do amido nos procedimentos de determinação de suas características físico-químicas.

Na Tabela 1 estão apresentados os resultados dos experimentos com os valores médios e desvio padrão para cada parâmetro analisado na caracterização físico-química da crueira.

Tabela 1: Resultado dos parâmetros analisados para caracterização da crueira

\begin{tabular}{cc}
\hline Parâmetros & Resultados \\
\hline Umidade (\%) & $30,06 \pm 0,46$ \\
Cinzas (\%) & $1,52 \pm 0,03$ \\
Lipídeos (\%) & $0,54 \pm 0,03$ \\
Fibra bruta (\%) & $3,43 \pm 0,23$ \\
Proteínas (\%) & $2,19 \pm 0,16$ \\
Amido (\%) & $82,00 \pm 0,58$ \\
$\mathrm{pH}$ & $5,00 \pm 0,20$ \\
\hline
\end{tabular}

Os resultados obtidos na Tabela 1 demonstram valores semelhantes aos apresentados por Neves [5] no que diz respeito ao teor de amido (81,1 $\pm 0,18 \%)$, lipídeos $(0,44 \pm 0,01 \%)$ e pH $(5,4)$. Entretanto, demonstra diferenças com relação aos demais parâmetros físico-químicos pesquisados.

Carvalho [11] descreve a crueira como "farinhão" e determinou os valores de 73 a 78, 1,52 e 5,00 para os teores de amido, cinzas e $\mathrm{pH}$, respectivamente. Os valores descritos por Carvalho [11] divergem dos valores obtidos para a caracterização da crueira do presente estudo (Tabela 1), com exceção do parâmetro $\mathrm{pH}$.

Analisando a composição físico-química de outros resíduos da agroindústria da mandioca, a crueira foi a que apresentou maior percentagem de amido $(82,0 \pm 0,58)$. Estudos realizados por Pandey [12] demonstraram um teor de amido para o bagaço da mandioca em torno de 40-60\% e Jyothi et al [13] em torno de 45-50\% para o mesmo resíduo. Na manipueira, resíduo líquido obtido durante a produção da farinha de mandioca, o teor de amido encontrado foi de $1,17 \%$ [14] e $9,42 \%$ [15].

O valor obtido para o teor de cinzas na crueira (Tabela 1) demonstrou ser baixo quando comparado com valores obtidos para o mesmo componente em outros resíduos vegetais, como a palha de arroz e palha de trigo, que contêm 17,5\% e 11,0\% respectivamente [12].

Os resultados da caracterização físico-química da crueira apresentam variações entre os diferentes estudos citados na literatura. Contudo, essas diferenças se devem a utilização de diferentes variedades de cultura de mandioca, de condições climáticas e de solo da região de produção, bem como a diferença de metodologia de análise dos parâmetros utilizados por cada autor [5]. No entanto, é possível constatar que em todos os estudos a crueira apresenta-se como um resíduo com alto teor de amido e baixo teor de cinzas, o que a torna um resíduo com alto potencial para uso em processos de bioconversão utilizando culturas microbianas.

\section{CONCLUSÃO}

O estudo da caracterização físico-química da crueira é, portanto, relevante para avaliar o potencial de aproveitamento desse resíduo, agregando valor ao mesmo e contribuindo com as questões ambientais e sociais envolvidas na produção e disposição final do mesmo. As características físico-químicas determinadas no presente trabalho quando comparadas com outros estudos, demonstram que a crueira possui alto teor de amido $(82,00 \pm 0,58)$ e baixo teor 
de cinzas $(1,52 \pm 0,03)$, tornando-a um substrato potencialmente adequado aos processos biotecnológicos de bioconversão.

\section{AGRADECIMENTOS}

Agradecemos ao Departamento de Engenharia Química da Universidade Federal de Sergipe e a CAPES (Coordenação de Aperfeiçoamento de Pessoal de Nível Superior) pelo apoio financeiro proporcionando recursos materiais para desenvolvimento do presente trabalho.

\section{REFERÊNCIAS BIBLIOGRÁFICAS}

1. Valle TL, Lorenzi JO. Variedades melhoradas de mandioca como instrumento de inovação, segurança alimentar, competitividade e sustentabilidade: contribuições do instituto agronômico de campinas (IAC). Cad Ciênc Tecnol. 2014 Jan; 31(1): 15-34, doi: 0104-1096

2. Pereira AA. Diversidade genética, genômica e filogeografia de mandioca (Manihot esculenta Crantz): implicações para a dispersão do cultivo ao longo dos principais eixos fluviais da bacia amazônica brasileira [dissertação]. Piracicaba (SP): Universidade de São Paulo, Escola Superior de Agricultura Luiz de Queiroz; 2015. 27-33p.

3. Ceratti M. Mandioca: um cultivo milenar reinventado pelos índios terenas [Internet]. São Paulo (SP): Revista Eletrônica El País; 2015 Ago [publicado em 2015 Ago 8]. Disponível em: http://brasil.elpais.com/brasil/2015/08/08/politica/1439065484_035712.html

4. Eduardo AV, Josefino FF, Luiz JCBC, Juaci VM , Francisco DF. Avaliação de genótipos de mandioca industriais em área de Cerrado do Noroeste de Minas Gerais. Revista Ceres. 2015 Out; 62 (5): 453 459, doi: 10.1590/0034-737X201562050005

5. Neves VJM.Uso do resíduo da produção de farinha de mandioca (crueira) na produção de álcool fino [dissertação]. Botucatu (SP): Universidade Estadual Paulista "Júlio de Mesquita Filho"; 2004. 55p.

6. Biazus T. Safra de 2015 deve ser 4,4\% maior que em 2014[Internet]. Mato Grosso do Sul (MS): MS Notícias; 2015 Fev [publicado em 2015 Fev 13]. Disponível em: http://www.msnoticias.com.br/editorias/agronegocios/safra-de-2015-deve-ser-44-maior-que-em2014/55901/

7. Araújo NC, Guimarães PLF, Oliveira SJC, Lima VLA, Bandeira FA, Araújo FAC. Quantificação da geração de resíduos em uma casa de farinha no Estado da Paraíba. Rev Monogr Ambient. 2014 Dez; 13 (5): 3793-3799, doi:10.5902/22361308.

8. Pregnolatto W, Pascuet NS. Normas analíticas do Instituto Adolfo Lutz: métodos químicos e físicos para análise de alimentos. São Paulo: Instituto Adolfo Lutz; 1985. 533 p .

9. Zenebon O, Pascuet NS. Normas Analíticas do Instituto Adolfo Lutz.v.1: Métodos físico-químicos para análise de alimentos. São Paulo: Instituto Adolfo Lutz, 2005. 1020 p.

10. Carvalho GGP, Fernenades FEP, Pires AJV. Métodos de determinação dos teores de amido e pectina em alimentos para animais. Rev Eletrôn Vet. 2006 Jan; 8(1):1-16, doi: 1695-7504

11. Carvalho JOM. Subprodutos da mandioca - Composição dos resíduos sólidos. Porto Velho(RO): Empresa Brasileira de Pesquisa Agropecuária; 2005 Dez. 1 p, doi: 14768

12. Pandey A, Soccola CR, Nigamb P, Soccolc VT. Biotechnological potential of agro-industrial residues. II: cassava bagasse. Bioresource Technol. 2000 Ago; 74(1): 81-87, doi:10.1016/S09608524(99)00143-1.

13. Jyonti NA, Sasikiran K, Nambisan B, Balagopalan C. Optimisation of glutamic acid production from cassava starch factory residues using Brevibacterium divaricatum. Process Biochemis try. 2005 Nov; 40(11): 3576-9, doi:10.1016/j.procbio.2005.03.046.

14. Camili EA. Tratamento da manipueira por processo de flotação sem uso de agentes químicos [dissertação]. Botucatu (SP): Universidade Estadual Paulista, Faculdade de Ciências Agronômicas; 2007. 52p.

15. Cereda MP. Processamento e utilização da mandioca. $1^{\circ}$ ed. Cruz das Almas: Embrapa Mandioca e Fruticultura Tropical; 2005. Capítulo 1, Produtos e Subprodutos; p. 15-60, doi: 8573833106 